\title{
EFECTO DEL BENCILAMINO PURINA EN MEDIO LIQUIDO SOBRE LA TASA DE MULTIPLICACION IN VITRO EN Dioscorea alata
}

\section{EFFECT OF BEN CILAMINO PURINE O N IN VITRO MULTIPLICATION RATE OF Dioscorea alata IN LIQUID MEDIUM}

\author{
Janer M. Polo ${ }^{1}$, Irma R. Q uintero ${ }^{1}$ y Alfredo Jarma ${ }^{2}$
}

\begin{abstract}
RESU MEN
El ñame (Dioscorea sp.) es una planta de importancia nutricional y económica en regiones tropicales y subtropicales y se caracteriza por poseer tubérculos ricos en carbohidratos y vitaminas. El trabajo de investigación se realizó en el Laboratorio de BiotecnologíaVegetal de la Universidad de Córdoba durante el año 2001, con el objetivo de determinar el efecto de bencilaminopurina (BAP) adicionada al medio líquido en agitación constante $(120 \mathrm{rpm})$, sobre la tasa de multiplicación in vitro del ñame (Dioscorea alata). Se utilizó un diseño completamente al azar con 8 repeticiones, los tratamientos consistieron en tres concentraciones de BAP $\left(0.1,0.2\right.$, y $\left.0.3 \mathrm{mg} \mathrm{L}^{-1}\right)$ y un testigo al que no se adicionó BAP. A los 30 días después del establecimiento in vitro, se evaluó el número de nudos, hojas y raíces por explante (segmento nodal). Los resultados mostraron que no se presentaron diferencias estadísticas $(P<0.05)$ entre las dosis evaluadas, registrándose una tasa de multiplicación media de 2.5 nudos por planta, valores muy semejantes a las tasas obtenidas en multiplicación in vitro del ñame en medio sólido sin reguladores de crecimiento. Sin embargo, se observó un mayor desarrollo fisiológico en las hojas y longitud del tallo en el medio líquido sin reguladores de crecimiento. Con esto surge la alternativa de aplicar potencialmente la propagación clonal masiva del ñame sin agente gelificante en el medio de cultivo, lo que, sin duda bajaría los costos de producción significativamente.
\end{abstract}

Palabras Clave: Cultivo in vitro, Dioscorea, Fitohormonas, ñame, micropropagación.

\section{ABSTRACT}

The yam (Dioscorea sp.) is a plant of economic and nutritious importance in tropical and subtropical rainforest; it is characterized to be climber that possesses tubers rich in carbohydrates and vitamins. This research was done in the plant biotech lab of the U niversity of Córdoba (M ontería - Colombia) in 2001 , with the objective of determining the effect of four BAP dose $\left(0,0.1,0.2\right.$, and $\left.0.3 \mathrm{mg} \mathrm{L}^{-1}\right)$ on the in vitro multiplication rate of yam in a liquid medium. The number of shoot leaves and roots for explant

${ }^{1}$ Ingeniero Agrónomo. Asistente Investigación, Facultad Ciencias Agrícolas. U. de Córdoba. Tel: 7860055. Ext. 195. Ijanerpolo@latinmail.com; irquire@hotmail.com

2D ocente Investigador Universidad de Córdoba, Facultad de Ciencias Agrícolas. Tel. 7860055. Ext. 195. ajarma@sinu.unicordoba.edu.co - Grupo de Investigación Participativa para los Pequeños Agricultores de la Costa Atlántica. 
after 30 days in culture were evaluated using a complete randomized design with 8 replicates. The results showed no statistical differences among the treatments, with a rate of 2.5 shoot per subculture period very similar to the rates obtained in semi solid medium without hormones. However, it was noted a better physiologic development in the leaves and longitude of the shaft when using liquid medium without hormones. The results indicate that is possible to use liquid medium to in vitro multiply yam and lower the costs avoiding the use of the gelling agent.

Key Words: In vitro Culture, Dioscorea, cultivation media, yam, micropropagation.

\section{INTRO DUCCION}

El ñame pertenece a la familia Dioscoreaceae, que posee 5 géneros y alrededor de 750 especies. Las del género Dioscorea más cultivadas corresponden aD. alata, D. rotundata, D. cayenensis, D. esculenta, D. bulbifera y $D$. trífida, de las cuales la primera es la preferida en la producción de tubérculos para el consumo humano. En general las plantas pertenecientes a esta familia se caracterizan por ser trepadoras que poseen tubérculos carnosos ricos en carbohidratos (Perea y Buitrago, 2000).

En el mundo se conocen varias especies de ñame; sin embargo, en Colombia las más cultivadas son: Dioscorea alata y Dioscorea rotundata, las cuales se han sembrado cíclicamente a través del tiempo, utilizando una selección visual por parte de los cultivadores. Este proceso de propagación consecutiva sin que exista un programa de mejoramiento, ha originado una degeneración genética de la planta, con el consecuente deterioro en su sistema de adaptación y resistencia, panorama agravado por la falta de investigación en este sistema de producción.

En el Caribe Colombiano, el ñame es parte fundamental de la alimentación de las comunidades campesinas. Sin embargo, el cultivo se ha visto afectado en los últimos años por enfermedades causadas por hongos, entre las cuales sobresale antracnosis (Colletotrichum gloesporioides), debido a la susceptibilidad de las variedades cultivadas y la implementación de sistemas de monocultivo. Además, plagas como Xystus sp. y varios virus, causantes de efectos desfavorables, limitan los rendimientos y provocan drásticas reducciones del área cultivada (Corpoica, 1995).

El principal problema que enfrentan los productores de ñame en la región de la Costa Atlántica Colombiana se relaciona con la carencia de semilla asexual certificada de variedades resistentes $y / 0$ tolerantes a hongos y virus. Sin embargo, se han realizado algunos esfuerzos en este sentido como el Programa de Biotecnología Agrícola de Colombia (PBA) que, en proyectos conjuntos con la Universidad de Córdoba, U niversidad de Sucre y Corpoica regional 2, ha identificado este tubérculo como una de las especies fundamentales en la dieta de los campesinos costeños y ha adelantado investigaciones orientadas a la conservación genética de la especie, estudios agronómicos, producción de semillas de variedades certificadas y agroindustrialización del mismo.

El sistema de propagación clonal es considerado como una de las técnicas más avanzadas y de aplicación práctica para la producción de semilla asexual y tiene como propósito, obtener características agronómicas deseables y de buena sanidad, que conlleven a mejorar la producción, rentabilidad y la calidad de vida de los agricultores de la región. 
El nuevo reto que enfrenta la industria del cultivo de tejidos en el mundo cada día, incluye los altos costos de producción y eficiencia, siendo el agente gelificante el que conlleva a elevar considerablemente estos costos por unidad propagada. (AitkenChristie et al., 1995).

Sandal et al. (2001), en busca de aumentar la proliferación de brotes en segmentos nodales de té (Camellia sinensis), emplearon el medio Murashige y Skoog (MS) (1962) líquido, suplementado con Bencilaminopurina (BAP) o Tidiazurón (TDZ). Los investigadores observaron un progresivo incremento en la tasa de multiplicación en 7.6 y 20 veces en comparación con el medio sólido, con dosis de $8.88 \mu \mathrm{M}$ BA y $5 \mu \mathrm{M}$ TDZ respectivamente a las 4 semanas bajo condiciones de agitación y/o estacionalidad.

$\mathrm{Ng}$ (1986), estudió el efecto de diferentes citoquininas (Kinetina, BAP y 2 ip) en dos niveles (5 y $10 \mathrm{mg} \mathrm{L}^{-1}$ ) y dos estados físicos del medio de cultivo (sólido y líquido) en el desarrollo de plántulas de ñame a nivel in vitro, usando segmentos nodales. En todos los tratamientos obtuvo alto número de nudos por explantes creciendo en medio líquido. Cuando crecían en éste medio el desarrollo de los nudos era rápido y vigoroso, a las 6 semanas se obtenían tasas de multiplacación de 5 a 8 nudos por plántula.

Puche y Rodríguez (1999), trabajando en micropropagación de Dioscorea alata CV Diamante 22, registraron que la mejor respuesta se obtuvo con MS básico sin hormonas en estado sólido con 2.4 nudos por planta de tasa de subcultivo.

Por otra parte, trabajos realizados por varios investigadores (Mantell et al., 1980; Ammirato, 1984; Espitia y Quintero, 1999; Polo y Vergara, 2001) utilizando como medio básico MS, consideraron como exitosa la consistencia sólida ( $0.6 \%$ agar) con la adición de algunos reguladores de crecimiento según el objetivo propuesto.
El propósito del presente trabajo fue estudiar el efecto del medio líquido en agitación constante suplementado con tres dosis de bencilaminopurina (BAP), con el fin de identificar al ternativas sostenibles y rentables para la multiplicación clonal masiva in vitro de plántulas sanas de ñame en la Costa N orte Colombiana.

\section{MATERIALES Y METODOS}

La investigación se llevó a cabo en el Laboratorio de Biotecnología Vegetal de la Universidad de Córdoba - Colombia, en el primer semestre de 2001. Se evaluó el efecto de tres niveles de bencilaminopurina (BAP) como suplemento del medio Murashige y Skoog (MS) en estado líquido en agitación constante sobre la tasa de multiplicación del ñame a nivel in vitro.

\section{Material vegetal}

La selección del material vegetal provino de plántulas de ñame, cultivar 003 de 30 días de edad y establecidasin vitro en medio semi sólido, a partir de las cuales se tomaron segmentos nodales de aproximadamente 2 $\mathrm{cm}$ de longitud.

\section{Medio de cultivo y condiciones de incubación}

La siembra se realizó en frascos de vidrio, con $15 \mathrm{ml}$ de medio nutritivo MS en estado líquido, suplementado con $1 \mathrm{mg} \mathrm{L}^{-1}$ de Tiamina, $50 \mathrm{mg} \mathrm{L}^{-1}$ de Cisteina, $100 \mathrm{mg} \mathrm{L}^{-1} \mathrm{de}$ mioinositol, $30 \mathrm{mg} \mathrm{L}^{-1}$ de Sacarosa, los 3 niveles diferenciales de BAP $(0.1,0.2$ y 0.3 $\mathrm{mg} \mathrm{L}^{-1}$ ) y un testigo al que no se le adicionó el regulador de crecimiento. $\mathrm{El} \mathrm{pH}$ del medio se ajustó a 5.8 antes de esterilizarlo $\left(121^{\circ} \mathrm{C}\right.$ y $1 \mathrm{Kg} \mathrm{cm}^{-2}$ ) por 20 minutos. Las condiciones de incubación de los explantes fueron bajo un fotoperiodo de 16 horas luz y 8 horas de oscuridad, con una temperatura promedio de $28^{\circ} \mathrm{C}$. 


\section{D iseño experimental y variables de estudio}

El diseño experimental utilizado fue completamente al azar con 4 tratamientos (las tres dosis y el testigo) y ocho repeticiones. La unidad experimental constó de un segmento nodal. Las variables consideradas fueron número de nudos, hojas y raíces por planta emitidas a los 30 días después del establecimiento a nivel in vitro. Los datos se corrieron bajo el paquete Statiscal Analysis System (SAS) y cuando fue necesario, las pruebas de comparación de medias se hicieron bajo el test protegido de DMS a un nivel del $5 \%$ de probabilidad.

\section{RESU LTADOS Y DISCUSION}

\section{N úmero de hojas por planta}

No se presentaron diferencias estadísticas en el número de hojas $(P<0.05)$ al comparar las dosis de BAP y el testigo (Tabla 1). Lo anterior sugiere que esta variable es influenciada por el genotipo y que las dosis de la citocinina utilizada no ejerce una influencia importante sobre ella. Estos resultados son similares a los reportados por Puche y Rodríguez (1999), quienes obtuvieron los mayores promedios (2.4 hojas) a los 42 días en las plantas donde no se agregó hormona. Vale la pena considerar que la información reportada por los autores mencionados, se registró con D . alata Cv Diamantes 22 en un medio MS básico. Asimismo, es importante destacar que estos resultados se registraron 12 días después de lo encontrado por este trabajo.

\section{Formación de nudos por planta}

En la formación de nudos por planta, no se presentaron diferencias estadísticas para las tres dosis de BAP y el testigo, sugiriendo que la hormona, a los niveles evaluados, no tiene efecto sobre esta variable como se muestra en la Tabla 1.

Tabla 1. Número de hojas, nudos y raíces por plantas (30 días d.d.e) del cultivar 003 de ñame bajo cuatro niveles de BAP, en condicionesin vitro. Universidad de Córdoba, 2001.

\begin{tabular}{|c|c|c|c|}
\hline $\begin{array}{c}\text { Concentración BAP } \\
\left(\mathbf{m g ~ L}^{-1}\right)\end{array}$ & $\begin{array}{c}\text { N úmero } \\
\text { de hojas }\end{array}$ & $\begin{array}{c}\text { Número } \\
\text { de nudos }\end{array}$ & $\begin{array}{c}\text { Número } \\
\text { de raíces }\end{array}$ \\
\hline 0.1 & $3.2 \mathrm{a} *$ & $2.5 \mathrm{a}$ & $0.09 \mathrm{a}$ \\
\hline 0.2 & $2.6 \mathrm{a}$ & $2.2 \mathrm{a}$ & $0.81 \mathrm{a}$ \\
\hline 0.3 & $2.5 \mathrm{a}$ & $2.2 \mathrm{a}$ & $0.78 \mathrm{a}$ \\
\hline 0.0 & $3.5 \mathrm{a}$ & $2.5 \mathrm{a}$ & $1.22 \mathrm{~b}$ \\
\hline
\end{tabular}

* Promedios con la misma letra son iguales estadísticamente de acuerdo al test protegido de DMS (5\%).

Con base en lo anterior, potencialmente se podría multiplicar ñame a nivel in vitro en un medio sin hormona, en estado líquido con agitación constante como una excelente alternativa. Esto sin duda, tendría un efecto positivo sobre los costos de producción clonal masiva en biofábricas.

Durante el desarrollo de la investigación, se observó un mayor crecimiento de hojas y longitud del tallo en el medio líquido sin hormonas (M S básico). Resultados similares fueron reportados por $\mathrm{Ng}$ (1986), el cual logró tasas de multiplicación de 5 a 8 nudos por plántula en un período mayor de establecimiento (6 semanas), empleando kinetina, 2 ip y BAP como fuente de citocininas. 
Estos resultados sugieren que una determinada respuesta morfogenética (regeneración de hojas, brotes, tallos y nudos) a nivel in vitro, está determinada por la interacción de numerosos factores, tales como el genotipo, tipo de explante, estado fisiológico del mismo, y la composición química del medio nutritivo. En este último, la interdependencia entre citocininas y auxinas en el control del desarrollo morfológico in vitro de muchas especies vegetales, constituye la base de gran parte de los protocolos de micropropagación, como lo indicaron Ammirato (1984) y Brown y Thorpe (1986).

\section{N úmero de raíces por planta}

La emisión de raíces no mostró diferencias estadísticas entre los tratamientos tal como lo indica la tabla 1. Estos valores se consideran muy bajos debido a que estos medios de cultivo no contienen auxinas. Aún así se destaca el medio MS básico sin hormonas (testigo), mostrando que el ñame tiende a formar raíces en condicionesin vitro, posiblemente atribuido a la existencia de contenidos endógeno de auxinas en este tipo de tejido.

\section{CONCLUSIONES}

La tasa de multiplicación in vitro del ñame encontrada en el estudio en medio líquido M urashige y Skoog (M S) sin hormonas (2.5 nudos), es semejante a la reportada en la multiplicación convencional en medio sólido por Puche y Rodríguez en 1999. Sin embargo, se observó un desarrollo vigoroso en la formación de órganos (hojas y tallos), condiciones favorables que permitirán tener mayor éxito en la multiplicación in vitro.

Los resultados permiten inferir que es posible realizar multiplicación in vitro de Dioscorea alata en medio líquido, sin un agente gelificante, lo que podría tener consecuencias positivas al reducir los costos de producción.

\section{BIBLIO G RAFIA}

Aitken-Christie J.; Kozai T. y Takayama S. 1995. Automation in plant tissue culture. General introduction and overview En: Aitken- Christie, J.; Kozai T. y Smith M. (Ed). Automation and Enviromental Control in Plant Tissue Culture. Kluwer Academic, The N etherlands, p.1-15

Ammirato, P. 1984. Yams. En: Ammirato P.; Evans D .; Sharp W. y Yamada Y. (Ed). Hand Book of Plant Cell Culture, Crop Species. N ew York, p.327-354
Brown, C. y Thorpe, T. 1986. Plant Regeneration by organogenesis. En: Vasil, I.K. (Ed). Cell Culture and Somatic Cell Genetics of Plant. Academic Press, 0 rlando.

Corpoica 1995. Estudio base para identificación de líneas de acción del trabajo en biotecnología con pequeños y medianos productores agropecuarios en la Costa Atlántica. Programa de Biotecnología Agrícola y Programa Nacional de Estudios Socioeconómicos. Regional 2 de Corpoica, p. 8-10 
Espitia, A. y Quintero, I. 1999. Estandarización de la técnica de micropropagación por embriogénesis somática en ñame (D. alata var. Diamates 22). Tesis Ingeniero A grónomo. Universidad de Córdoba, Montería, p.72

Mantell, S.; Haque, S. y Whitehall, A. 1980. Apical meristem tip culture for eradication of flexous rod viruses in yams (Dioscorea alata). Tropical Pest M anagement. 26(2): 170-179.

Murashige, T. y Skoog, F. 1962. A revised medium for rapid growth and bioassays with tobacco tissue cultures. Physiol Plant 15: 473-497

$\mathrm{Ng}, \mathrm{S} .1986$. Virus climation in sw eet potato, yam and cocoyam. In: proceedings of Regional Root Crops Workshop. Cali, p.97-102

Perea, M. y Buitrago, G. 2000. Aplicaciones de la Biotecnología Agrícola al cultivo del Ñame. En: Guzmán, M. y
Buitrago, G. (Ed). Ñ ame Producción de semillas por Biotecnología. U niversidad N acional de Colombia, Santa fe de Bogotá, p.17-32

Polo, J. y Vergara, C. 2001. Estandarización de la técnica del cultivo de meristema apical para la limpieza de virus en ñame (Dioscorea alata). Tesis Ingeniero Agrónomo. U niversidad de Córdoba, Montería, p. 75

Puche, F. y Rodríguez, L. 1999. Estandarización del medio de cultivo para la propagación in vitro del ñame (D ioscorea alata L. C.v. Diamante 22) vía cultivo de segmentos nodales. Tesis Ingeniero Agrónomo. Universidad de Córdoba, Montería, p. 82

Sandal, I.; Bhattacharya, A. y Sigh, P. 2001. An efficient liquid culture system for tea shoot proliferation. Plant Cell Tiss O rg Cult 65: 75-80 